\title{
Introducing the new senior editor for sociology
}

Published online: 23 June 2018

(C) Springer Nature B.V. and International Society for Plant Pathology 2018

For some time, there has been a feeling among editors of Food Security and others that Nutrition and Sociology do not fit together particularly well under the auspices of a single Senior Editor, although there are situations when both topics are encompassed by single papers e.g. those dealing with the distribution of food within some patriarchal families. So, while Andy Jones will continue to look after nutritional papers, from this issue onwards we are very pleased to welcome Conny Almekinders as Senior Editor who will be dealing with the more sociological papers. Conny works as a social scientist in the Knowledge, Technology and Innovation (KTI) group in Wageningen University, the Netherlands. She obtained a $\mathrm{PhD}$ from the same university, based on her potato crop physiology research, carried out at CIP (International Potato Centre), Peru. She worked for many years on issues related to seed systems and farmers' management of plant genetic resources, including participatory plant breeding and in situ con- servation. Her shift in focus from plants to farmers, the interaction among them and with scientists, has brought her into socio-technical studies of agriculture.

https://www.wur.nl/en/Persons/dr.ir.-CJM-ConnyAlmekinders.htm

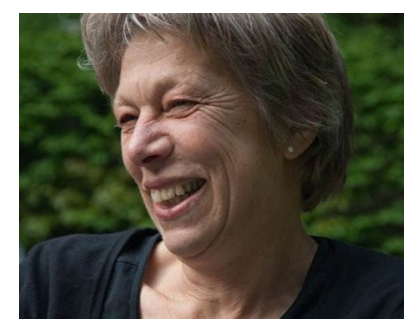

